\title{
Emotionally Contentious Social Movements: A Tri-VAriate Framework
}

\author{
RAY SIN \\ University of Kansas
}

\begin{abstract}
After decades of seeing emotions as irrational and unimportant, scholars in social movements are beginning to value the role of emotions in social movements. This paper contributes to the burgeoning literature on emotions and contentious politics by proposing a synthesized tri-variate framework called the "emotional tripod." The emotional tripod consists of three mutually constitutive "legs" that explain the origins of emotions (emotional habitus), the process of intensifying and transforming emotions (emotional effervescence) and the quality of the emotions generated (affective/reactive emotions). This paper empiricizes the framework by looking at the visual materials produced by PETA. Lastly, this paper briefly critiques the efficacy of emotions in generating collective action.
\end{abstract}

\section{Introduction}

From provocative ads depicting nude models with the caption "We'd rather go naked than wear fur," to a heart-warming children's comic that illustrates "A Cow's Life" in sentimental details, are small but pertinent examples of the range of evocative materials the People for the Ethical Treatment of Animals (PETA) are responsible for. Since its inception in 1980, their membership has grown from less than 100 in 1980 (Plous 1991) to over 500,000 in 1995 (Kruse 1998). Now, as the largest animal rights organization in the world, they announced that they have more than two million members. ${ }^{1}$

${ }^{1}$ http://www.peta.org 
To achieve their four goals of ending factory farming, animal experimentation, fur industry and animal exploitation in the entertainment industry, the strategies and tactics used by PETA are anything but moderate. Instead, the provocative ads and heart-warming children's comics indicate that it is emotions that PETA are trying to evoke. How, then, do we understand the role of emotions and social movements sociologically? Does the literature provide an adequate framework to understand the relationship between emotions and social movements? To address these questions, this paper proposes a tri-variate framework that situates emotions in the center of understanding its role in engendering collective action. The first section gives a historical overview of the role of emotions in social movement literature. The second section introduces the tri-variate framework that I call the "emotional tripod." The third section contextualizes the framework empirically. Lastly, I briefly critique the efficacy of emotions in contentious politics.

\section{Literature Review}

\section{The Irrational and Emotional-Collective Behavior}

Traditionally, emotions in social movements are regarded as "a contagion" (Le Bon 1960[1896]) and associated with "irrationality" (Park 1972) that turns rational individuals into a deranged collective. This is what McPhail (1991) calls the "transformation hypothesis". Essentially, this advocates a symbolic interactionist perspective whereby aggrieved individuals are driven to frustration and negative emotions are reinforced by crowd dynamics (Blumer 1939; Miller and Dollard 1941).

Alternatively, another traditional viewpoint sees emotions as indicative of individual pathologies. This "predisposition hypothesis" (McPhail 1991) is critical of placing primacy on group dynamics and proposes that researchers should not mistakenly substitute individuals with the collective. Allport $(1920 ; 1924)$ argues that Le Bon and his contemporaries are guilty of "the group fallacy" and suggests instead that individuals are driven by innate desires to satisfy a primordial instinct to seek out gratification. Because of their pathologies, these individuals are extremely susceptible to social movements.

Additionally, heavily influenced by psychological reductionism, scholars assume that movement activists are predisposed to violence (Allport 
1924), are socially dysfunctional (Lasswell 1930), alienated (Kornhauser 1959) and under social strain (Smelser 1962). Holistically, this presents a misguided view that emotions have little room in the realm of social movements except to describe activists as irrational, insane and socially dysfunctional. As succinctly summarized by Goodwin, Jasper, and Colletta (2000:69), "the more emotional an individual (or crowd) becomes, the less rational s/he (or they) become, ipso facto." This recognition, albeit misinterpreted, still gave emotions some room for discussion within the literature.

\section{Resource Mobilization Theory-Collective Action}

A new paradigm shift marginalized the position of emotions by differentiating between (irrational) collective behavior and (rational) collective action. McCarthy and Zald $(1973 ; 1977)$ elaborate that the resource mobilization approach downplays the centrality of grievances as the fundamental catalyst of social movements. They believe that social discontent is prevalent in any society at any time but it is only with the availability of resources that grievances turn into collective action. With that, scholars began to demarcate clearly the difference between collective behavior and collection action.

Charles Tilly (1978) defines collective action as the purposive action that people undertake collectively to pursue common interests. He rejects the traditional collective behaviorist view that participants are irrational and enraptured with insanity but embraces the idea that their actions are purposive and participants are rational. Tilly highlights the importance of resources and organization, and underscores that collective action is not spontaneous, irrational and unstructured; but instead, the very opposite. Such reasoning gave birth to the concept of social movement organizations to recognize the organizational, structural, rational and objective-oriented nature of mobilization. Like McCarthy and Zald (1973; 1977), Tilly emphasizes that resources are more important.

From the position of resource mobilization theory, collective action connotes rationality, decisiveness, planning and organization. Movement actors are seen as active agents that shape, lead, participate and define the different aspects of social movements. Collective behavior, on the other hand, suggests irrationality, spontaneity and disorganization in which 
activists play a passive role. An important caveat is that not all scholars arguing from the collective behavior position sees social actors as passive and irrational. Tuner and Killian (1957) subscribe to an "emergent norm" hypothesis whereby the motivations behind collective behavior are heterogeneous and diverse. For them, actors are caught up in a symbolic communication process called "milling", where members communicate in an interactive fashion that creates norms, common visions, shared beliefs and alternate realities. They depart from other collective behaviorists because they recognize the agency of movement actors and the active role that they play.

With the hitherto dominance of resource mobilization theory, the vocabulary articulating collective action became preoccupied with being organized and rational. As a result, emotions are pushed further back into the background due to its traditional association with irrationality. To use the analogy of throwing the baby out with the bathwater, because of the imperative to reject irrationality, emotions are thrown out of the equation.

\section{Emotionally Contentious: Emotional Tripod Framework}

To rectify the association of emotions with irrationality, scholars began to give validation to the role of emotions in social movements (Flam 1990a; 1990b). Recent scholarship tries to resuscitate the idea that collective action and emotions are not mutually exclusive. Instead, they are simultaneously rational and emotional processes that structure, motivate and form the basis of strategic action (Jasper and Poulsen 1995; Jasper 1997, 1998; Aminzade and McAdam 2002; Kim 2002). Notwithstanding this, most studies conducted on emotions and social movements still lack some form of coherence and unity (Goodwin et al. 2000:78). This paper integrates these disparate works into a unitary framework by arguing that there are three important legs (emotional effervescence, emotional habitus and affective/reactive emotions) within the "emotional tripod" that work in a mutually constitutive fashion, albeit each with varying degrees, that accounts for the role emotions play in social movements.

\section{First Leg: Emotional Effervescence}

Randall Collins (1990) proposes an interesting concept of "emotional energy" in understanding the dynamics between emotions and collective 
action. He conceptualizes emotional energy on a continuum with high positive feelings and low negative feelings on either polemic end. Subsequently, he suggests that in every highly mobilized social movement, the strategies undertaken by activists engage in "high ritual density," which creates two kinds of emotional transformation that ultimately culminate into "collective effervescence" (Collins 2001:28-29). However, I argue that the term "emotional effervescence" is a more accurate depiction. Nonetheless, the two kinds of emotional transformation refer to the "amplification of the initiating emotions" and "transmutation of initiating emotion into something else." The former refers to strategies in augmenting the initiating sentiment (e.g., anger) into a stronger element (e.g., indignation) and the latter depicts that the initiating emotion (e.g., anger) reconfigures into the (emotional) basis for collective solidarity within the group. This brings to the forefront that organic emotions can become a strategic basis for mobilization.

The major flaw is that Collins (2001) assumes that emotions exist $a$ priori and does not give attention to where "initiating emotions" come from. Bearing in mind that a more complete sociological understanding of emotions cannot merely suggest that emotions exist in a vacuum, but that emotions are constructed by an interplay between a myriad of elements such as biology, culture and agency. There is no doubt that "emotional effervescence" results in collective action but then the pertinent question is, where does the initiating emotions come from?

\section{Second Leg: Emotional Habitus}

The initiating emotions can be found in Anne Kane's (2001:254) idea of "emotional habitus," which is appropriated from Pierre Bourdieu (1977). Kane elaborates that this emotional habitus alludes to Scheff's (1997) notion that in many societies, we organize and operate our lives and actions according to certain "master" emotional paradigms. In this sense, these emotional habitus are historically constructed as well as situationally contingent. Emotional habitus quintessentially encompass initiating emotions because of the cultural and historical undercurrents. The concept of emotional habitus is instrumental in explaining why the consumption of certain images evoke emotions; and, it is the transformation of these initiating "emotional energies" that lead to collective action. 
This is especially so if familiar imageries are manipulated. The process of the deliberate appropriation and manipulation of shared cultural symbols to mock the original meaning is what Carducci (2006) means by "culture jamming." By focusing exclusively on the subversiveness of "culture jamming," Carducci forgets that emotional energy gets stirred up from the consumption of the manipulated cultural image as well. Then, how is that emotional energy harnessed? How does one account for the quality of that emotional energy?

\section{Third Leg: Affective/Reactive Emotions}

(1998) employs the concepts of affective and reactive emotions in his study of protests and emotions. Affective emotions are more permanent and abiding feelings, based, for example, on the love for one's family or on close ties with individuals and groups, and are central components of social life. Such emotions are linked to Affect Control Theory, which explains the "(efficacy of) persuasion in terms of its appeal to people's fundamental sentiments about things in society" (Berbrier 1998:440). Reactive emotions, on the other hand are more short-termed responses to events, discoveries and decisions (Jasper 1998) and are evoked by external stimuli. An example would be pro-life groups using pictures of bloodied fetuses as part of their strategy ${ }^{2}$. An affective emotion could be empathy from someone who has gone through an abortion, leading him or her to become a life-term member or even a spokesperson for the group. Alternatively, a reactive emotion might just be shock and he or she may simply donate some money to the cause and not participate on a more substantive or regular manner.

What is important to note is that affective and reactive emotions are not distinctly separated entities but instead are two ends of a continuum. This continuum is important because it allows one to recognize the diversity of collective action that could occur due to emotions. What it highlighted is that the quality of emotional energy stimulated is fluid and because of that, the type of mobilization that ensues has countless possibilities. Consequently, this moves researchers away from only focusing on large-scale public protests as testimony of the effectiveness of emotions. Subtle affective or reactive emotional responses, such as undertaking a vegan diet or

${ }^{2}$ Examples of those pictures could be found on http://www.prolife.com/ 
throwing away one's fur coat, otherwise remain undetected by researchers. In part, this framework hopes to give some currency to the many small lifestyle changes that are impacted by emotions.

\section{Emotional Tripod and Collective Action}

Putting the three legs together, the emotional tripod framework (diagrammatically represented in Figure 1) accounts for the process in which emotions are deployed as a strategic means for social movements to further their cause. Initiating emotions within emotional habitus are purposively stimulated, and in the case of PETA, by vilifying commonly shared imageries. The manipulation of these imageries become the basis for emotional effervescence to occur, which transforms initiating emotions into stronger emotions that lie somewhere in between the reactive/affective continuum. To what extent does this influence the capacity for collective action to arise?

Jasper (1998:106) argues that a moral shock "helps a person think about [one's] basic values and how the world diverges around them." I would add that this is an interactive and continuous process. The provocation of emotions ultimately aims to engender a critical reflection on one's own belief system and worldview. Is the mistreatment of animals inhumane? Is my fur coat an indication of my participation in animal cruelty? How different is eating a steak from eating my pet dog? In terms of protest and evident from this research, soliciting the public's emotions through "culture jamming" is strategically used by activists to promote some form of critical self-reflexivity that becomes the basis for collective action to occur. The catalyst for that to occur are emotions. The process of how that translates

\section{Figure 1}

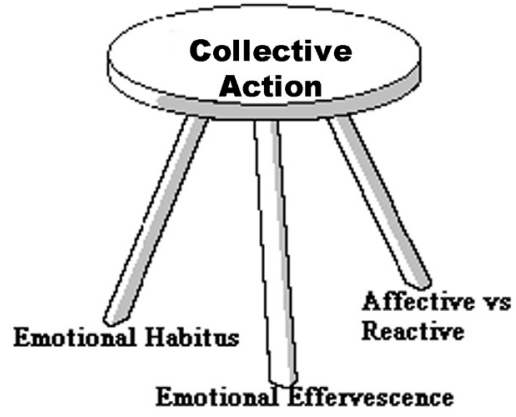


from just emotional sensations to collective action is what the "emotional tripod" aims to elucidate. One has to note that this "emotional tripod" is a strategy in hope of achieving some form of collective action. By stimulating the emotions embedded in a particular emotional habitus to achieve a level of emotional effervescence that lies in between the affective/reaction continuum is what social movements intend to accomplish. Whether it leads to a favorable outcome is something that no one can foresee or guarantee.

\section{Methodology}

Previous research demonstrates that animal rights participants are predominately recruited by their exposure to the visually explicit materials used by animal rights organizations (Herzog 1993; Herzog, Dinoff and Page 1997; Jasper and Nelkin 1992; Jasper and Poulsen 1995; Groves 1997; Lowe and Ginsberg 2002). Thus, to understand the role of emotions in collective action, one has to focus on the imageries deployed by PETA. Therefore, this paper examines PETA's use of pictures, videos, flyers, leaflets, publications and any other paraphernalia incorporated in their crusade against animal cruelty. These secondary data ${ }^{3}$ are collectively termed as visual rhetoric and are obtained predominately from PETA's website. Some visuals are part of a broader thematic campaign such as "McCruelty," JesusVeg.com and others. Additional materials are drawn from peta2.com, which is their teen-oriented website.

\section{Provoking the Emotional Habitus}

\section{Historical Events-The Holocaust}

DeLuca and Peeples (2002) pointed out that social movements have discovered the power of images, which helps to frame, expound and garner awareness for the movement through "common spectatorship" (Hariman and Lucaites 2003). PETA explicates this by re-appropriating and vilifying the symbols associated with fast food chains. This vilification process, also known as culture jamming, is significant as Goodwin et al. (2001) argue

\footnotetext{
${ }^{3}$ According to the disclaimer made by PETA, with the exception of third party ownership or copyright, copying, reproduction, or redistribution of any of the documents, data, content, or materials for personal, noncommercial use is enthusiastically encouraged. (http://blog.peta.org/).
} 


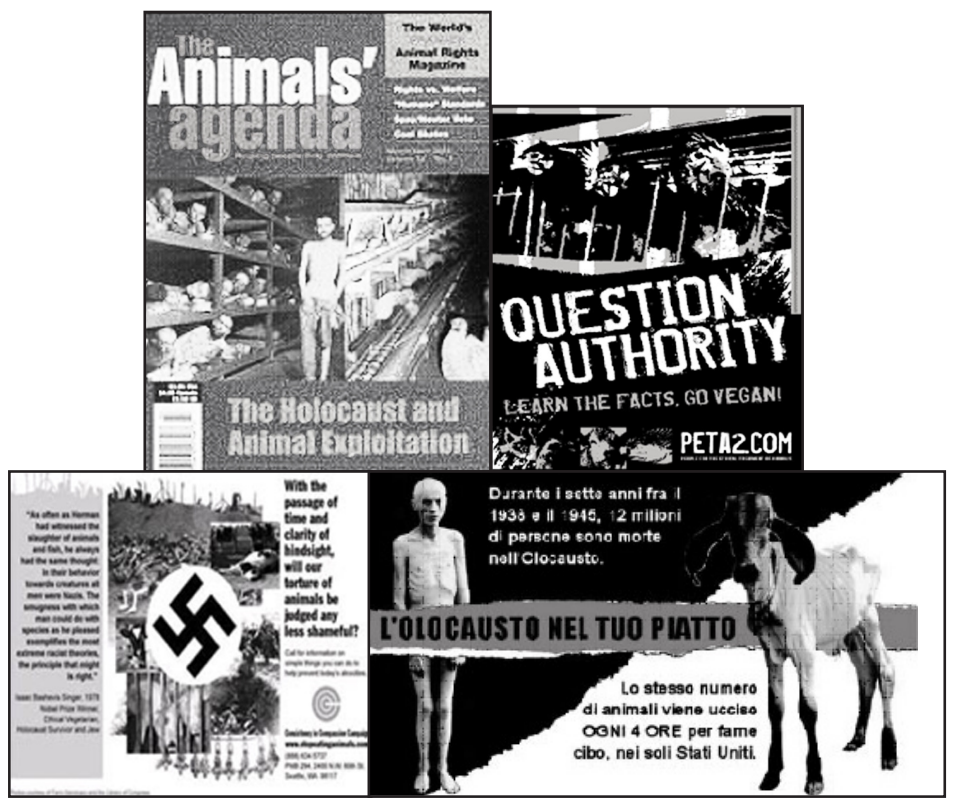

Figure 2

that the demonization of opposition fuels powerful emotions for social movements.

Known as "Holocaust on Your Plate" (CNN 2003), PETA associates the merciless massacre of animals used in the slaughterhouse industry as akin to the plight of the Jews in Nazi concentration camps. Citing Newkirk (Washington Post 1983):

"Six million Jews died in concentration camps, but six billion broiler chickens will die this year in slaughterhouses."

By invoking poignant historical events such as the Nazi Holocaust, PETA intends to make the victimization of the Jews at the concentration camps parallel to that of the treatment of animals at the slaughterhouse (see Figure 2) The likening of livestock production to the Holocaust is an attempt not only to demonize the very act of consuming meat, it more accurately attacks and re-frames the very basis of animal slaughter for human consumption. It makes the Nazi concentration camps and slaughterhouses commensurate. Subsequently, this facilitates stimulating and/or augmenting the same abhorrence and contempt inherent in the emotional habitus of the 
genocide and translating it onto the fast food industry. Thus, PETA aims to intensify those strong initiating emotions (such as abhorrence) through the process of emotional effervescence by alluding slaughterhouses to concentration camps in an attempt to forge an emotional basis for organizing collective action. At the same time, PETA desires to induce some form of reactive emotions such as disgust and shock so as to stimulate some form of short term collective action, such as protest. As eloquently articulated by PETA's vice-president of communications and reinforced by PETA's Jewish representative, respectively:

"Nazi concentration camps were modeled after slaughter houses ... [i]t's shocking, it's startling, it's very hard to look at. We're attacking the mindset that condones the slaughter of animals"--Lisa Lange (CNN 2003)

"The very same mind-set that made the Holocaust possible - that we can do anything we want to those we decide are 'different or inferior' - is what allows us to commit atrocities against animals every single day" -Mark Prescott (CNN 2003)

\section{Cultural Icons-Symbols and Figures}

Most fast food chains have icons that represent their establishments. These icons do not only possess cultural meaning, they too have emotional significance. For example, Happy Meals evoke a strong sense of happiness, joy and familial warmth and in that sense, they are considered an emotional habitus. In a strategic attempt to harness those emotions, animal rights activists hand out gory leaflets and posters that denigrate these icons and by extension transform initiating emotions, such as familial warmth, into something negative. Examples include PETA's depiction of Wendy as an insane and wicked murderer with blood stained hands and Colonel Sanders as a pathological knife-wielding butcher who is unapologetically enjoying inflicting pain onto chickens (see Figure 3). Similarly, the vilification of publicly recognized founders of fast food chains is also used during demonstrations. A common protest tactic employed by PETA in its demonstrations outside Kentucky Fried Chicken (KFC) restaurants has been a dramatic re-enactment of the brutal massacre of a chicken mascot by Colonel Sanders (see Figure 3). Additionally, PETA has not only caricatured the names of these establishments (for example, by turning McDonald's into McCruelty; Burger King into Murder King; see Appendix A), even 


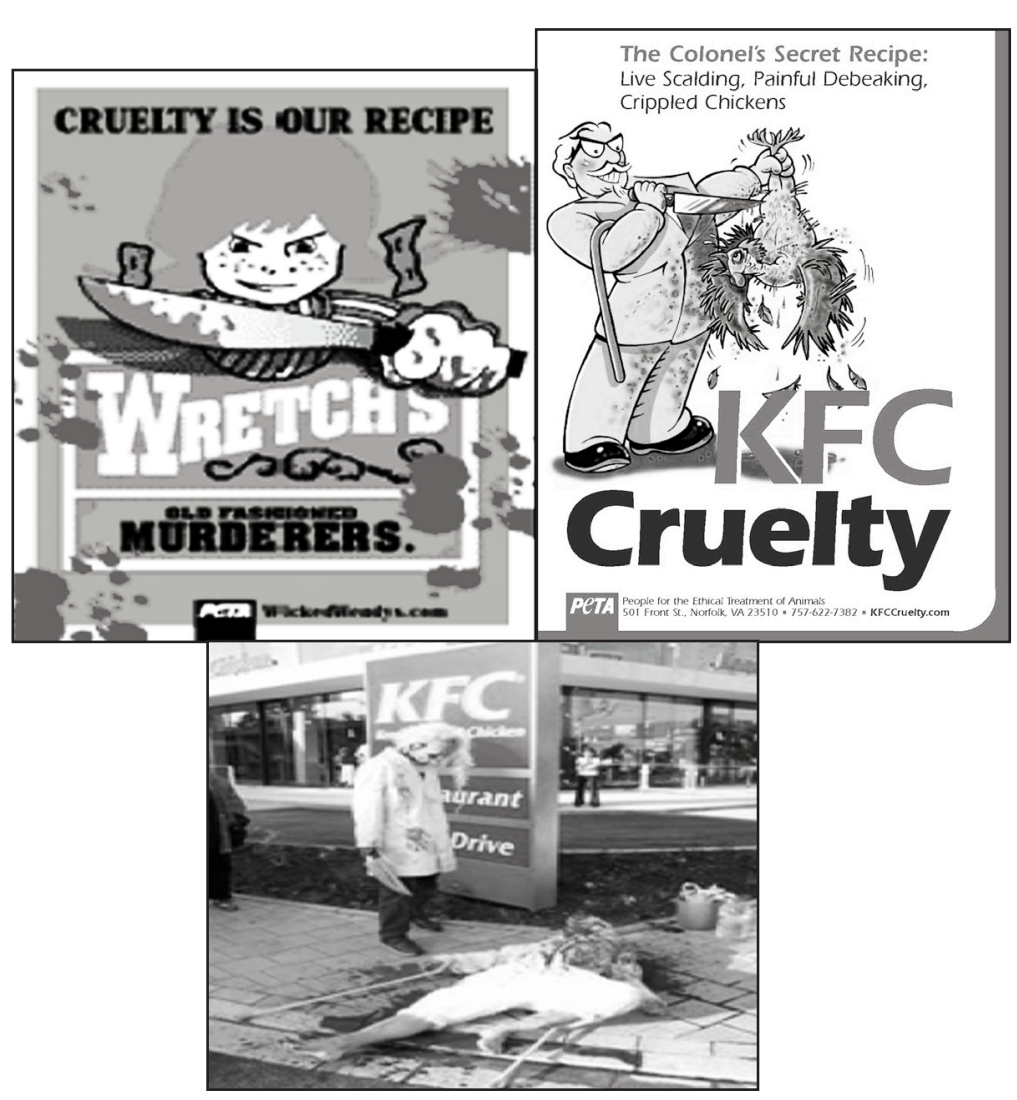

Figure 3

the names of food stuff available at these establishments are disparaged: Happy Meals (McDonald's) are termed as Unhappy Meals and Buckets of Chicken (KFC) are re-named as Buckets of Blood (see Appendix B).

By re-appropriating the names, icons and founders of the establishment and (re)presenting them gorily, PETA has created a "condensation symbol" that "neatly capture[s] - both cognitively and emotionally — a range of meanings and convey a frame, master frame, or theme (Jasper and Poulsen $1995: 498)$. Furthermore, they are indulging in the deliberate manipulation of the emotions associated with these symbols. These condensation symbols such as the deranged Colonel Sanders, pathological Ronald McDonald or wicked Wendy are signifiers to the abominable atrocities inflicted upon these animals used as economic resources in the fast food industries. The 
aim is to instill reactive emotions such as a sense of disgust, shame, anger and maybe even hatred in viewers. The familial happiness associated with Happy Meals or innocence associated with Wendy becomes qualitatively transformed into outrage.

Therefore, through these condensation symbols, PETA aims to engender a moralistic attack against the integrity of these fast food establishments and orchestrate moral shocks as a corollary. Moral shocks are the sine qua non of PETA's movement. Moral shocks reiterate the urgency and saliency of their agenda and help to formulate, through the use of visual rhetoric, a sense of crisis, shock and outrage that provides the emotional impetus to mobilize (Jasper and Poulsen 1995). From here, we can see that the ultimate goal for the explicit and provocative use of visual rhetoric is to evoke emotions which are used as an instrument to gain momentum and publicity for their cause. As elaborated by Ingrid Newkirk, President of PETA, in USA Today (1991):

"Probably everything we do is a publicity stunt ... we are not here to gather members, to please, to placate, to make friends. We're here to hold the radical line."

\section{Critically Evaluating the Duality: Nature/Culture; Man/Animal} What Would Jesus Do?

At the most basic level, PETA argues against the Judeo-Christian tradition that animals, being the embodiment of nature, are subordinate to humans (White Jr. 1967; Singer 2001). Expounding on this, Newkirk comments,

"Animal liberationists do not separate out the human animal, so there is no rational basis for saying that a human being has special rights. A rat is a pig is a dog is a boy. They're all mammals."

Religious figures in themselves possess a significant amount of emotional habitus. The deliberate manipulation of the positive emotions associated with iconic figures such as the Pope or Jesus is strategic because they are bound to evoke strong emotions. And by reframing these religious connotations, PETA aims to transfer and intensify the emotions

${ }^{4}$ Washingtonian Magazine, 1 August 1986, pg. 115 


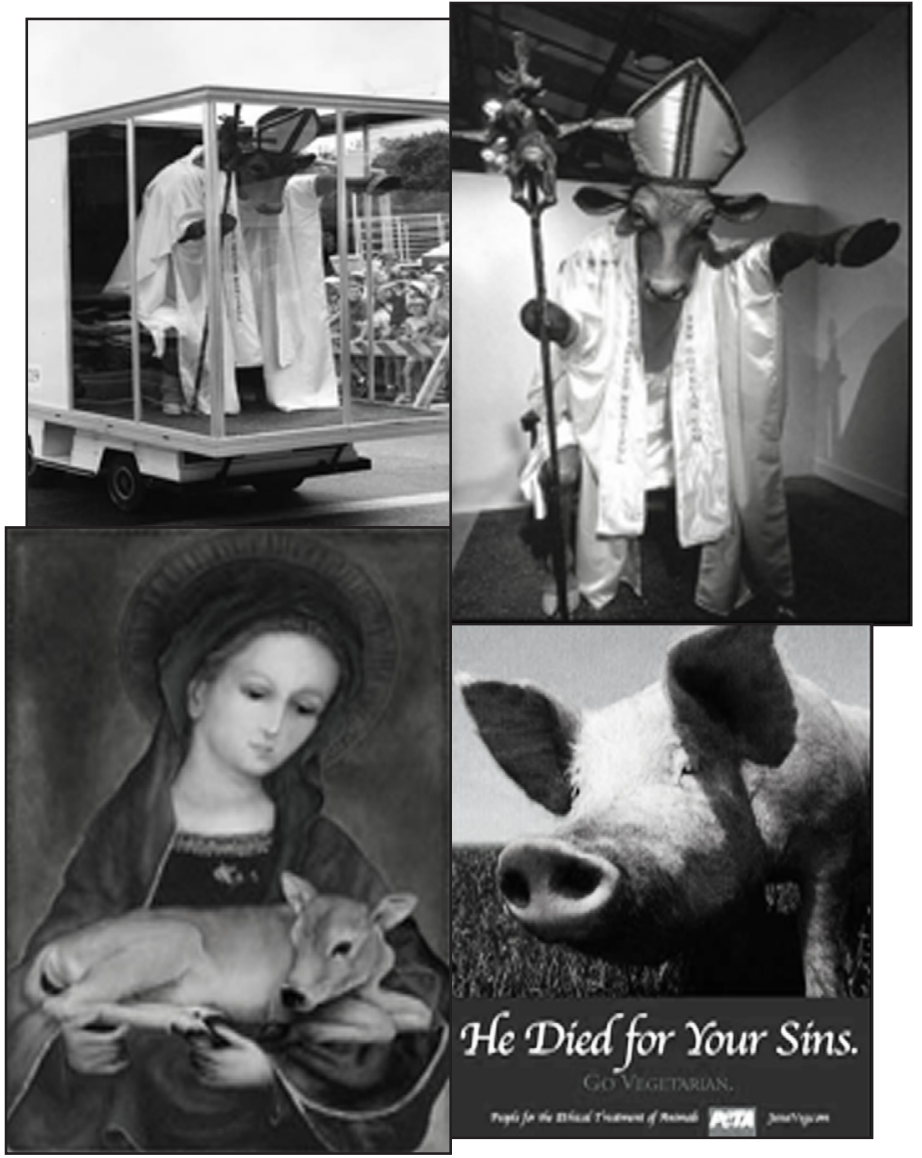

Figure 4

associated with religion onto animals. With reference to Figure 4, PETA adopted vilified caricatures derived from Biblical references such as the "Cow Pope" and turning Jesus into a pig or a calf. PETA has also publicly announced that their latest spokesperson enlisted in their cause is Jesus ${ }^{5}$ (see Appendix C). Not only does PETA desire to undermine the conventional Judeo-Christian attitude that is inherently homocentric, PETA also wishes to challenge people to "view the world from another animal's point of view, to imagine what it must mean to be bred, manipulated, tortured and then slaughtered in the most excruciatingly painful and distressing

${ }^{5}$ http://www.jesusveg.com/ 
ways" $"$ This helps to dissolve the dichotomy between nature and culture and underscores that the very act of consuming meat is culturally determined and not irrevocably natural.

Concomitantly, the very act of incorporating highly sensitive material adapted from religion and (re)presented blasphemously, again illustrates that PETA overtly endeavors to stimulate controversies and to evoke emotions from the public. Specifically, PETA indicates that their cause is an 'immaculate concept' (see Appendix D). This intentionally aims to stir up shame, disgust and revulsion in those that eat meat; but concurrently, seeks to arouse pleasure, gratification and pride in vegetarians. The result helps create more enduring affective emotions that become the basis for solidarity between activists. This is strategic especially since research attests that the Judeo-Christian tradition and religiosity reinforce the discourse of man's superiority over non-human animals (Flynn 2001; Jerolmack 2003; DeLeeuw et al. 2007). At the same time, it demonstrates the fluidity of emotions that can be stimulated and transformed through emotional effervescence. The emotional effervescence helps to create not only strong emotions to garner support but also provide some form of emotional ballast through the construction of affective emotions, such as pride to forge camaraderie.

Significantly, the duality of emotions instigated by PETA that instills positive emotions to those who adhere and negative emotions to those who deviate, also helps to re-align the Judeo-Christian ethos onto the side of PETA. Through the irreverent parallels drawn between livestock and Jesus, PETA seeks to manufacture moral shock. As mentioned above, the emotional response to moral shock forces one to question one's worldview. In this example, alluding to the consumption of meat as the cannibalistic consumption of Jesus or the Pope helps one question the duality between man and animal.

\section{Humanizing Animals'Emotions}

To destabilize the perceived boundaries between man/animal, PETA advocates the use of visual rhetoric to anthropomorphize animals. In one of their most widely circulated videos, Meet Your Meat, they portray the animals found in slaughterhouses to possess human-like emotions. In one

${ }^{6} \mathrm{http}: / /$ www.peta.org/feat/cowpope/cowpope.html 


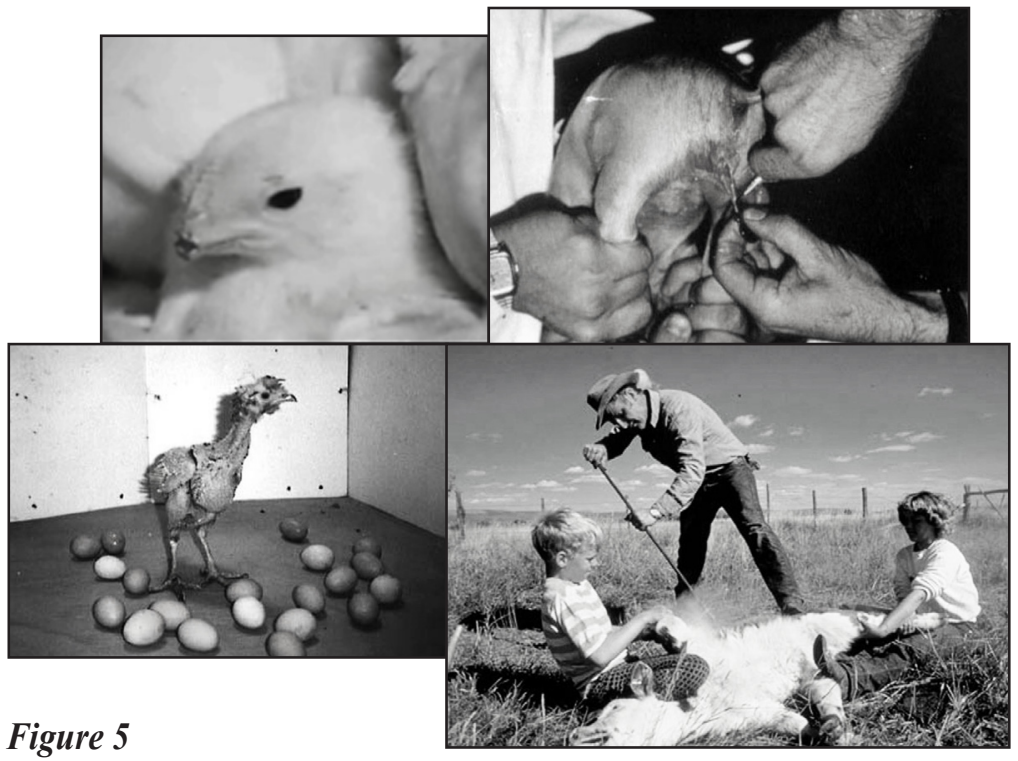

of the most disturbing scenes, which reveals the debeaking process of little chicks, the screen emphasizes the painful look of the chicks during the agonizing process of getting their beaks sliced off with a hot blade. Furthermore, in another scene that highlights their cramped living spaces, chickens were seen to display human-like reactions such as huddling together in fear. Torturous treatment of these animals were also situated in the foreground, including the castration and branding of cattle without any form of anesthesia; slamming pigs that are unfit to be sent to the slaughterhouse to death; and the starvation of chickens to force another egg laying cycle also known as molting (see Figure 5).

Humanizing animals by humanizing their emotions is another strategic attempt to exploit the emotional habitus of being a human being. As Jasper and Poulsen (1995:508) has highlighted, the selective display of the animals' suffering through 'painful' expressions is deliberate on part of PETA and is the master frame of the animal rights movement, which operates upon the praxis of anti-instrumental theme. More importantly, it is used as a motivational strategy (Jasper 2006) to stimulate emotional effervescence for collective action to occur. This concretizes PETA's campaign against the fast food industry as well as justifies the extreme and radical means 


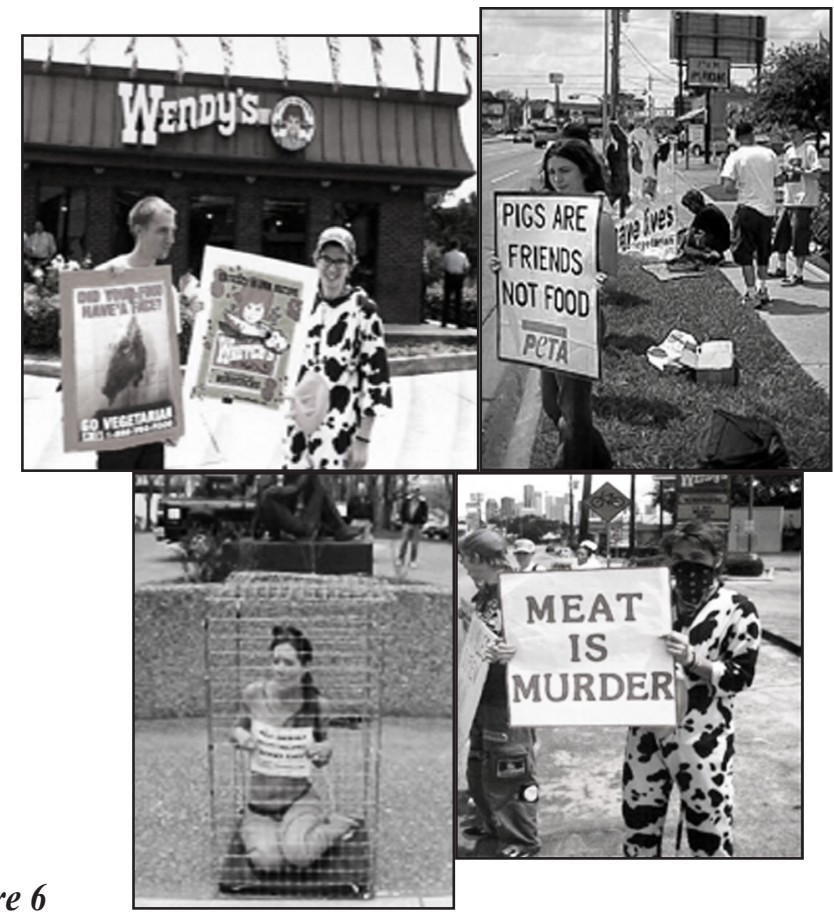

undertaken by PETA. Because the video highlights the atrocities inflicted on animals by humans empowered by large corporations, what PETA clamors for on a subliminal level is moral and ethical accountability. This echoes Jasper and Nelkin's (1992) assertion that the high rate of success of campaigning for animal rights is largely due to the fact that it is framed as a "moral crusade."

That moral crusade only makes sense through the clear exploitation of the emotional habitus of what it means to be human. By humanizing the animals through their emotions, it is easier for the public to identify and relate to the plight of these farm animals cognitively, morally and most importantly, emotionally. And, in doing so, forms the basis for emotional effervescence to occur by transforming, for example, empathy to indignation.

\section{Humanizing Animals by Animalizing Humans}

Demonstrations incited by PETA are also filled with protestors dressing up as animals (see Figure 6). Placing humans into the world of animals 
through dress has an effect of humanizing animals insomuch that it sets forth the notion that eating meat is tantamount to murder and specifically cannibalism. Moreover, PETA also attempts to encourage the general public to experience the animal world, by living in the same cramped cages that held these animals captive throughout their lives. By removing the barrier between human and animals, it is easier to capitalize on the emotional habitus associated with being human. Being forced to face the images and descriptions of the animals' living conditions and narrations of their pain, the public are "invited to identify with [the] treatment" of animals in the fast food industry (Atkins-Sayre 2003).

Visually explicit depictions of animals' poor living conditions, coupled with human(ized) attributes projected onto them, engenders what Jasper and Nelkin (1992) espoused as "sentimental anthropomorphism." Sentimental anthropomorphism creates an emotional (re)evaluation of animals to be regarded as more than just economic capital (see Appendix E). One could argue that this helps to generate an enduring affective emotion, such as empathy, to drum up support for the cause. At the same time, this acts as a mechanism for emotional effervescence to occur and thereby creates an emotional impetus for participation. Jasper (1997) reasons that this reactive emotion (i.e., "moral shock") is an effective recruitment strategy ${ }^{7}$ for social movements to maintain longevity.

To further underscore the plight of these anthropomorphized creatures, PETA also juxtaposes these painful narratives with more 'heart-warming,' romanticized and sentimental imagery that similarly seeks to blur the human-animal distinction. In their "Hidden Lives of . .. " portions of their anti-KFC web pages, it is not difficult to find such depictions-where esteemed human emotions of love, solidarity and familial bonding are 'imposed' on animal images (see Figure 7).

This is further emphasized with less than subtle explanations of what chickens and pigs are really like-_but it's true that some chickens like classic rock, while others like classical music; some chickens enjoy human company, while others are standoffish, shy, or even a bit aggressive" 8

\footnotetext{
${ }^{7}$ For a more nuanced understanding of how moral shocks affect recruitment, see Mika (2006). "Framing the Issue: Religion, Secular Ethics and the Case of Animal Rights Mobilization." Social Forces 85(2): 915-41

8 "The Hidden Lives of Chickens," PETA Online, http://www.peta.org/feat/hiddenlives/
} 


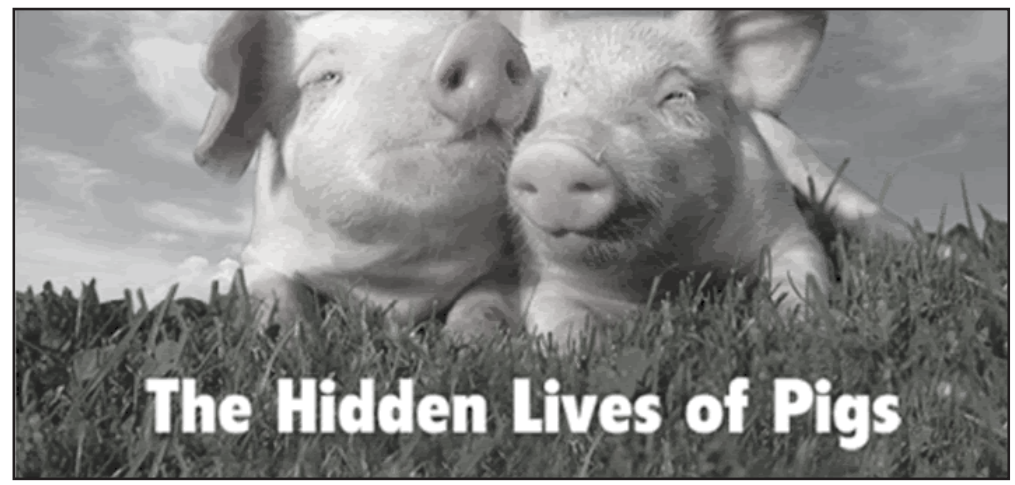

Figure 7

and pigs are "in their natural surroundings ... social, playful, protective animals who bond with each other, make beds, relax in the sun, and cool off in the mud." $"$

The visual combines with the rhetoric in an understated fashion to create impressions which serve to drive home the notions that animals are actually more human than we realize. In this manner, PETA seeks to induce the "affective" side of emotions within its viewers by appealing to the fundamental sentiments people use to sustain social life, such as feelings of love and affection for family members and important others. This is particularly effective for PETA's strategy, as Jasper (1998:14) notes that "affective reactions can occur without extensive perceptual and cognitive encoding, [and] are made with greater confidence than cognitive judgments ..." The cognitive complexities of deciding whether to support PETA's cause, which may involve issues of morality, ethics or truth, are subsequently diminished in importance and overridden by the flood of emotions that are induced through the tactics of anthropomorphism. This again follows the emotional tripod framework whereby the emotional habitus of being human is augmented through the visuals and the emotionally-laden rhetoric in hope of transforming initiating emotions such as pity into disgust or abhorrence that form the motivation and basis for collectivizing to occur.

The role of the chicken mascot used in demonstrations cannot be understated either, for what it effectively does is subtly blur the distinc-

9 “The Hidden Lives of Pigs", PETA Online, http://www.goveg.com/feat/Pigslife/ 


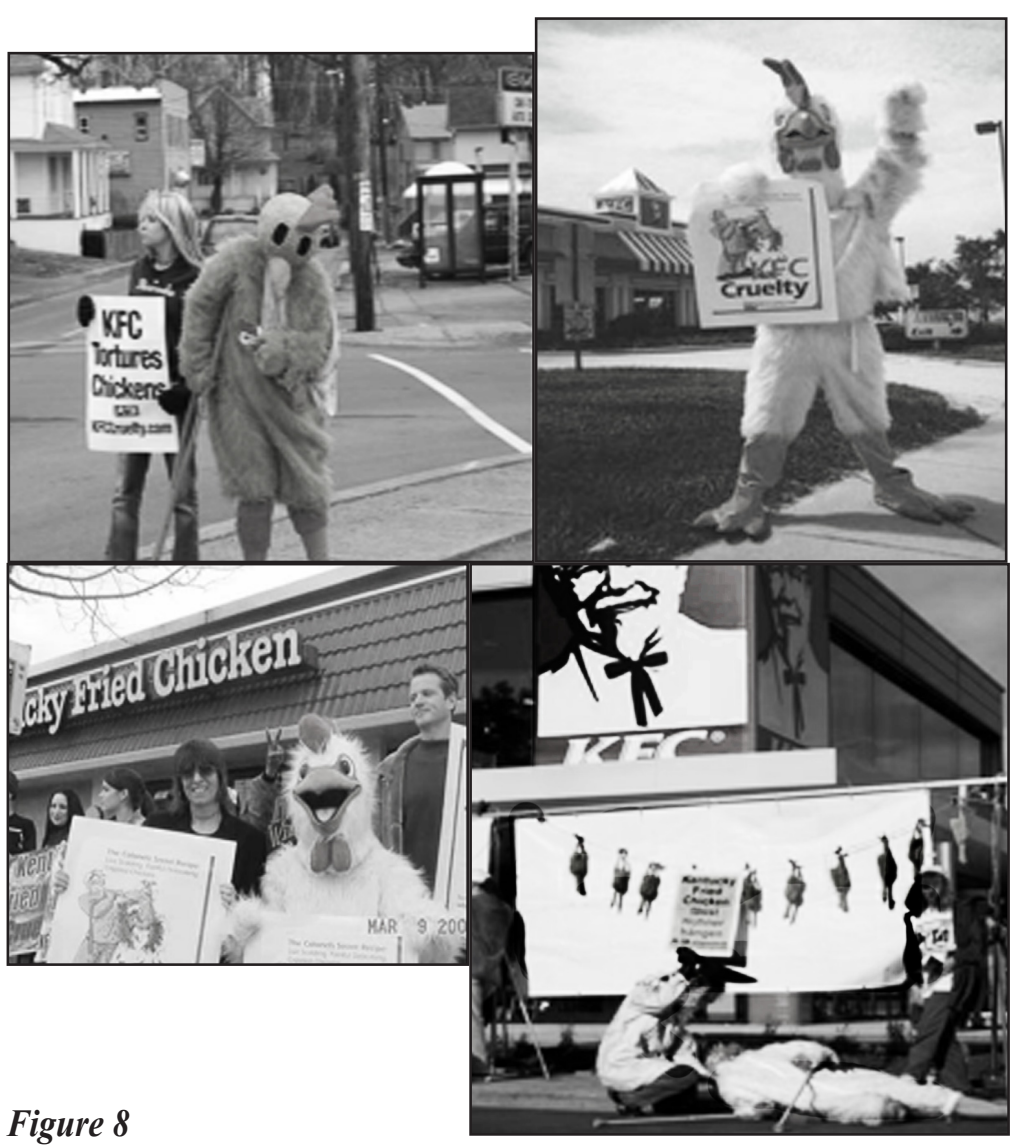

tion between the 'human' and the 'animal'. Other than being a victim in the drama, the chicken mascot at the protest also displays human-like behavior by walking on crutches, sitting in wheelchairs, giving out flyers and holding up posters (see Figure 8). This human-like figure is then horrifyingly bludgeoned, which on one level helps spectators draw profound similarities between chicken abuse and human abuse; but on another level, symbolically alludes to KFC committing heinous, 'murderous' crimes on its very patrons by serving them chicken parts from poorly raised and abused chickens.

In other words, this also authenticates Berger's (1980) and Baudrillard's (2002) positions that humans are more receptive to anthropomor- 
phized images of animals (cf. Atkins-Sayre 2003). As such, PETA is more than aware that these images of anthropomorphized animals arouse a sense of sympathy and empathy that is beneficial in establishing the credibility of and reiterating their cause. When animals are reconceptualized as capable of possessing human-like qualities like emotions, it forces individuals to rethink the human/animal divide. Showing that animals experience the same emotions as we do, especially pain, helps people to empathize with animals and this helps the movement to mobilize by transforming that empathy to fury. A visual image of a caged animal is expected to trigger similar emotional reactions to those of a caged child; and, because PETA capitalizes on this very aspect, shows that emotions are not an unintended consequence or a by-product of social movements but rather an essential ingredient that is calculatingly and intentionally crafted. Furthermore, with the accompanied caption and gore, it allows such initiating emotions to be transformed and transmuted to facilitate myriad forms of affective and reactive collective action such as donations, protests, speaking out, and among others.

At the same time, the process of eroding the boundaries between man/ animal by projecting human qualities, such as emotions, onto animals, helps to create new dualities that solidify their cause. Because the visual rhetoric deployed by PETA foregrounds the suffering of animals under the captivity of the fast food industry, this formulates a simple but effective bipolar structure based on good versus evil. Fast food franchises, humans that indulge in carnivorous habits and slaughterhouses are demonized and directly attributed as responsible for the callous treatment against animals. On the other hand, vegetarians, PETA and their members are elevated onto the pedestal of being righteous, fair and laudable and this gives currency to their protests and demonstrations, even if they are characterized by many to be radical and extreme. As espoused by Rodney Coronado, a convicted felon for 1992 Michigan State University firebombing and PETA beneficiary:

"A lot of people think that —Oh my god, that's going too far, you know. People can support bringing animals out of labs, but they can't support arson. Well, I'm sorry. I'm not here to, to please people. I'm not here to win the support of people. I'm here to represent my animal relations who are suffering this very second. And I don't care what anybody says about what I do to achieve their freedom."

- Speaking at SHAC (Stop Huntingdon Animal Cruelty) rally, Edison, New Jersey, November 30, 2002 
What is evident here is that a dual tier of emotions is created in the process. Firstly, positive emotions associated with PETA's relentless and unwavering actions and secondly, those that do not comply. It elevates the status of PETA and its followers whilst at the same time denigrates those who do not participate, who indulge in "contentious" consumption habits and companies that institutionalize animal cruelty. Regardless of whether it is positive or negative, those strong emotions become the motivation for collective action to arise.

\section{Evaluating Emotions}

This paper proposes a synthesized approach to emotions and social movements by making the cultural origins, the processural nature and the consequence of emotions apparent by focusing solely on the visual materials and strategies deployed by PETA. While emotions do play a paramount role in PETA's struggle for animal rights, emotions too create a backlash that undercuts their legitimacy.

Thus far, the emotional tripod accounts for the manufacturing of positive emotional responses to the movement. However, with every protest, demonstration and campaign waged against their "oppositional others" (e.g., fast food franchises), and through the use of visual rhetoric, an equivalent amount of emotional backlash is produced in the process. This backlash is what Burns (2005) termed as "moral veto."

With reference to the emotional tripod, the moral veto would fall somewhere near the extreme of the reactive end of the affective/reactive continuum. Having a strong emotional response no doubt helps to generate participation; but likewise, it can negatively impact the movement. Many stand out to criticize PETA's overt and provocative use of controversial visual rhetoric ranging from Ministers' denunciation of PETA's horrifying tactics against children (The Star Phoenix 2001); parents' contempt against PETA's educational methods for children (Your Kids, PETA's Pawns ${ }^{10}$ 2004); to condemnation by the Jewish community that characterized PETA's strategies and tactics to be anti-Semitic and highly insensitive (AntiDefamation League 2002). In their zealous pursuit to achieve their goals, PETA has also "alienated a growing group of humans ... (that) includes

\footnotetext{
${ }^{10}$ Article taken from The Consumer Freedom. http://www.consumerfreedom.com/ article_detail.cfm?article $=156$ [retrieved on 23 November 2006]
} 
fellow animal advocates, some of them former PETA employees" (The Virginian-Pilot 2000). As such, the use of emotions as a strategy alludes to a double-edged sword. Although emotions prove to be a highly effective tool in furthering PETA's cause, it also has repercussions that might emasculate what PETA represents. Such an argument is echoed by Burns (2005) in which movements might face a "moral veto" if the movement's objectives are not accepted by the more politically moderate middle class citizens, especially if the tactics are centered around stimulating emotions.

Similarly, though emotions of anger and moral outrage are especially useful in mobilizing supporters and framing the movement's cause, ultimately protesting and campaigning on the bases of emotion presents a shaky and unsound foundation. As Einwohner (1999) explains, using the example of the Progressive Animal Welfare Society's (PAWS) protest against recreational hunting, protesters who portray an emotional front are taken less seriously and even ridiculed than if they came from a more well-researched, 'rational' and substantiated position. Negative emotions like anger and outrage actually do more harm to the social movement by antagonizing the very corporations protesters are seeking to reach and effect change in. PETA's tactics and strategies are more often than not met with counter-resistance from corporations and organizations that criticize PETA's methods of preying on people's emotions to the point that people are not able to distinguish humane from abusive use of animals. ${ }^{11}$ This is also accompanied by allegations that PETA uses moles to unethically infiltrate organizations, and insidiously stage, film and photograph footage of abuse and mistreatment perpetuated by the very moles themselves. ${ }^{12}$ It is debatable as to who is really right, but the counter-resistance put up by corporations singling out the fallacies of PETA's emotional tactics certainly effects the credibility of their cause in no small measure.

On hindsight, the utilization of emotions as a devised rational strategy more or less has a 'short fuse.' To appease the emotional outrages incited

\footnotetext{
11 "PETA Manipulates Photos", Understanding Research at Palmer, Palmer College of Chiropractic. http://www.palmer.edu/News/peta_6_24_03/understanding_research_06_24_03.htm\#PETA\%20Manipulates\%20 Photos [retrieved on 21 November 2006]

12 "California businessman under siege by animal rights thugs", National Animal Interest Alliance online. http://www.naiaonline.org/body/articles/archives/ Sonoma_foie_gras_under_attack_by_AR_thugs.htm [retrieved on 21 November 2006]
} 
by PETA, all oppositional others have to do is corporate greenwash. An example would be the much-celebrated success by PETA against McDonald's in 2000. ${ }^{13}$ After McDonald's agreed to stipulate outlines that ensure enhanced animal welfare standards, PETA immediately withdrew all unfavorable material against them. However in February 2009, PETA started its "McCruelty" campaign again because of McDonald's refusal to mandate that its suppliers adopt a more humane form of slaughter ${ }^{14}$. Evidently, this illustrates that although emotions do play an important role in social movements, they are by and large short-lived. Because all that is necessary is just superficial corporate "greenwash" to placate the emotions and sentiments of PETA and their followers, the efficacy of emotions to sustain a social movement remains a question to be answered.

\section{Conclusion}

This paper proposes a unitary framework that synthesizes existing studies on emotions and social movements, entitled the "emotional tripod." The strength of this framework is that it accounts for the cultural origins of emotions and the process of their manipulation and transformation for collective action to arise. Emotions rarely exist in a vacuum and more often than we realize, emotions are predominately embedded in familiar visual imageries. Cognizant of this, PETA capitalizes on these underlying emotions in commonly shared visual rhetoric such as historical events, religious figures and cultural icons. In the case of PETA, it helps to further their cause because it allows the public to critically reflect upon their animal cruelty lifestyle; and concomitantly, it provides the emotional stimuli through the process of emotional effervescence, for mobilization to occur. In addition, the very concept of moral veto is a weakness of using emotions as a strategy. However, the weakness of this framework is ambiguity. Why does collective action not occur although emotions are strategically manipulated? Where is the delicate line, if it exists, between encountering moral veto and generating positive emotions to garner support? Apart from visuals, is it possible to deploy other means such as texts or discourses that can effectively mobilize emotions? These are future directions researchers can undertake to evaluate the centrality of emotions in social movements.

\footnotetext{
${ }^{13} \mathrm{http}: / / w w w . p e t a . o r g / a b o u t / v i c t o r i e s . a s p$ [Retrieved on 23 November 2006]

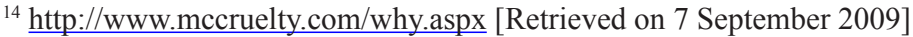


Appendix A

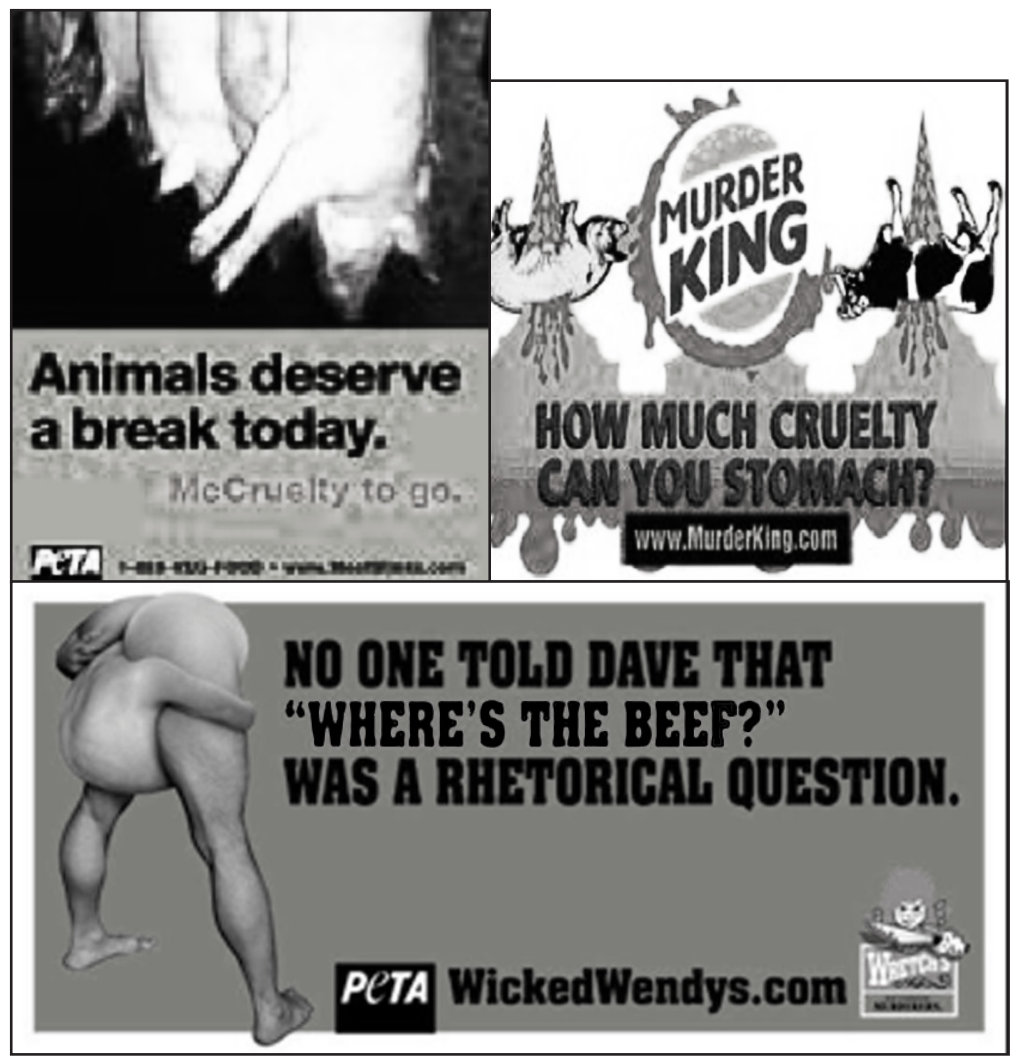

Appendix B

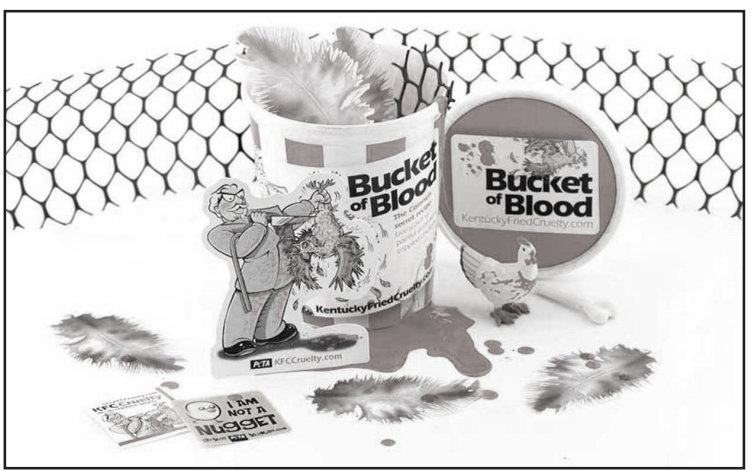




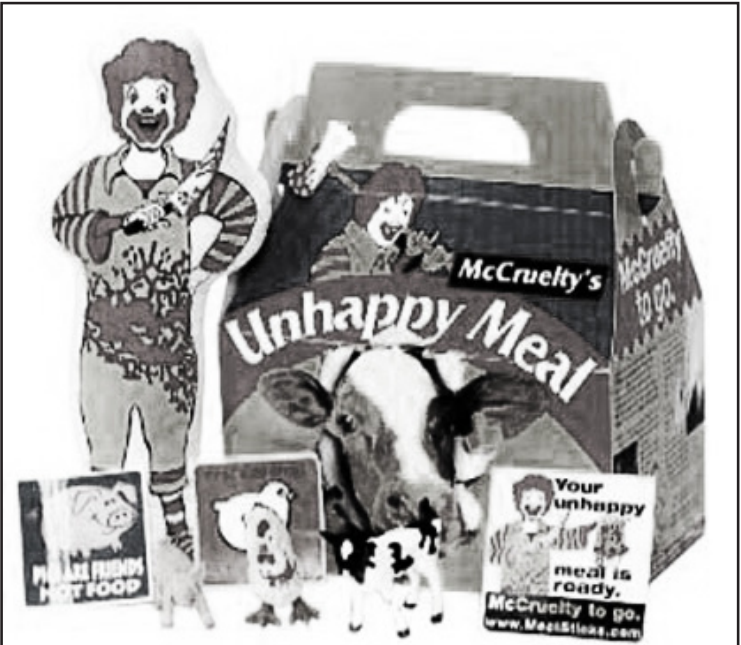

Appendix C
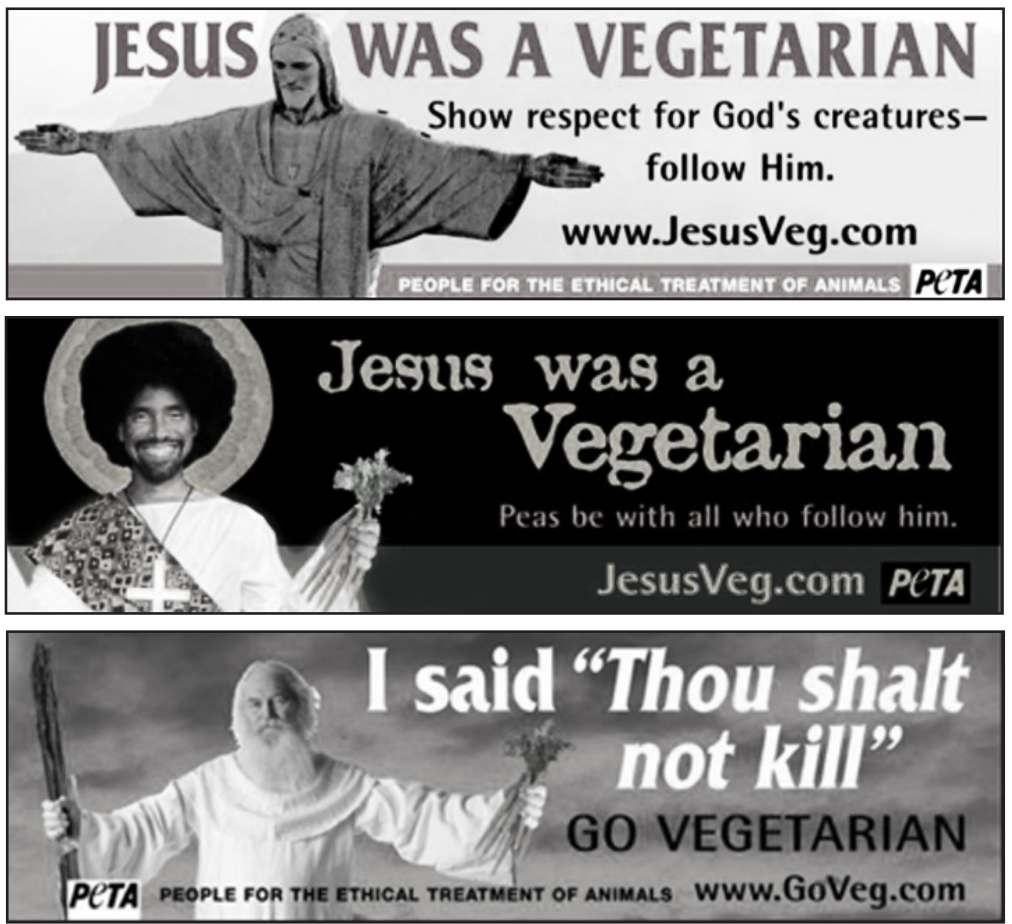
Appendix D

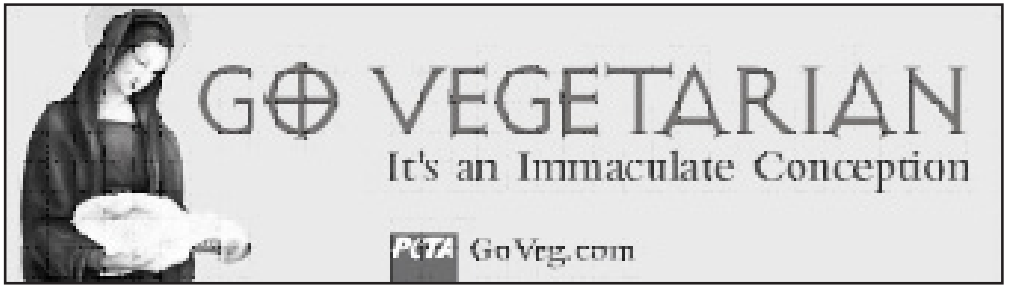

Appendix E

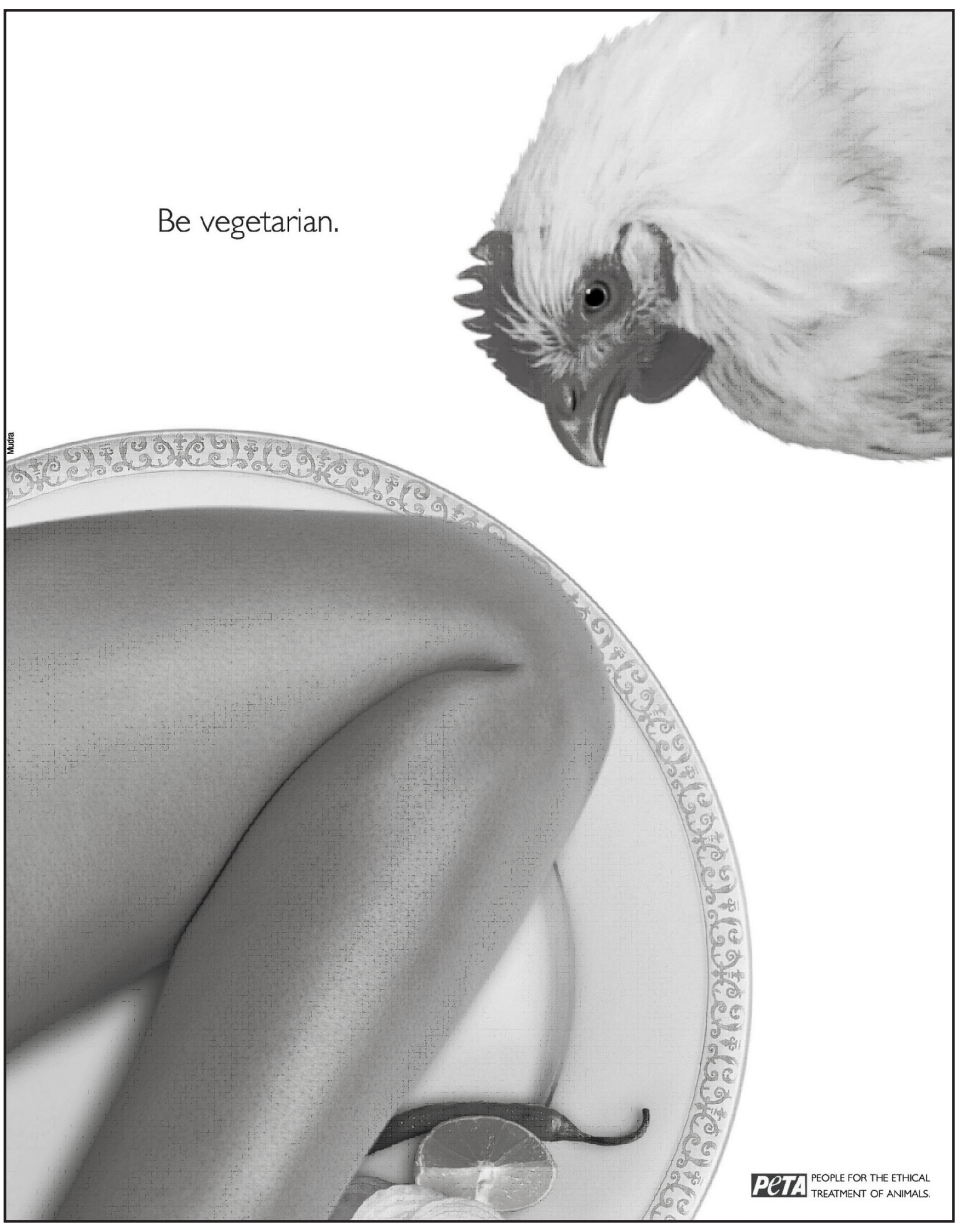




\section{Bibliography}

Allport, Gordon. 1920. "The Group Fallacy in Relation to Social Science." Journal of Abnormal and Social Psychology 19:60-73.

—. 1924. Social Psychology. Boston: Houghton Mifflin.

Aminzade, Ronald and Doug McAdam. 2002. "Emotions and Contentious Politics" Mobilization 7(2): 107-9.

Anti-Defamation League. 2002. "Holocaust Imagery and Animal Rights," 25 February. http://www.adl.org/Anti_semitism/holocaust_imagery. asp Atkins-Sayre, Wendy. 2003. Changing Images of Animals and Humans: PETA's Use of Visual Rhetoric. Electronic Paper: http:// www.arches.uga.edu/ $\sim$ was/petapaper.pdf.

Berbrier, Mitch. 1998. "Half the Battle: Cultural Resonance, Framing Processes and Ethnic Affectations in Contemporary White Separatist Rhetoric," Social Problems 45(4): 431-450.

Blumer, Herbert. 1939. "Collective Behavior." Pp. 219-280 in The Outlines of the Principles of Sociology, edited by Robert E. Parks. New York: Barnes and Noble.

Bourdieu Pierre. 1984. Distinction: A Social Critique of the Judgment of Taste. Cambridge: Harvard University Press.

Burns, Gene. 2005. The Moral Veto: Framing Contraception, Abortion and Cultural Pluralism in the United States. Cambridge, New York: Cambridge University Press.

Carducci, Vince. 2006. "Culture Jamming: A Sociological Perspective," Journal of Consumer Culture 6(1): 116-38.

CNN. 2003. "Group Blast PETA 'Holocaust' Project," 28 February Collins, Randall. 1990. "Stratification, Emotional Energy, and the Transient Emotions," in Theodore D. Kemper (ed.) Research Agenda in the Sociology of Emotions. Albany: State University of New York Press.

- 2001. "Social Movements and the Focus of Emotional Attention," in Jeff Goodwin, James M. Jasper and Francesca Polletta (eds.) Passionate Politics: Emotions and Social Movements. Chicago: University of Chicago Press.

DeLeeuw Jamie L., Luke W. Galen, Cassandra Aebersold and Victoria Stanton. 2007. "Support for Animal Rights as a Function of Belief in Evolution, Fundamentalism and Religious Denomination." Society \& Animals 15: 353-63.

DeLuca, Kevin. M and Jen Peeples. 2002. "From Public Sphere to Public Screen: Democracy, Activism and the 'Violence' of Seattle" Critical Studies in Media Communication, 19: 125-151. 
Einwohner, Rachel L. 1999. "Gender, Class and Social Movement Outcomes: Identity and Effectiveness in Two Animal Rights Campaigns," Gender and Society, 13(1), Special Issue: Gender and Social Movements, Part 2, pp: 56-76.

Flam, Helena. 1990a. "Emotional 'Man': I. The Emotional 'Man' and the Problem of Collective Action." International Sociology 5: 39-56.

—. 1990b. "Emotional 'Man': II. Corporate Actors as EmotionMotivated Emotion Managers." International Sociology 5: 225-34.

Flynn, Clifton. 2001. "Acknowledging the 'Zoological Connection': A Sociological Analysis of Animal Cruelty." Society and Animals 9(1): 71-87.

Goodwin, Jeff, James Jasper and Francesca Polletta. 2000. "The Return of the Repressed: The Fall and Rise of Emotions in Social Movement Theory." Mobilization 5(1): 65-84.

Goodwin, Jeff and Steven Pfaff. 2001. "Emotion Work in High-Risk Social Movements: Managing Fear in the US and East German Civil Rights Movements," in Jeff Goodwin, James M. Jasper and Francesca Polletta (eds) Passionate Politics: Emotions and Social Movements. Chicago: University of Chicago Press.

Groves, Julian McAllister. 1997. Hearts and Minds: The Controversy Over Laboratory Animals. Philadelphia: Temple University Press.

Hariman, Robert and John L. Lucaites. 2003. "Public Identity and Collective Memory in U.S. Iconic Photography: The Image of 'Accidental Napalm.' Critical Studies in Media Communication, 20: 35-66.

Herzog, Harold A. Jr. 1993. "The Movement is My Life: The Psychology of Animal Rights Activism.” Journal of Social Issues 49: 103-119.

—_, Beth Dinoff and Jessica R. Page. 1997. "Animal Rights Talk: Moral Debate Over the Internet." Qualitative Sociology 20: 399-418.

Jasper, James M. 1997. The Art of Moral Protest: Culture, Biography and Creativity in Social Movements. Chicago: University of Chicago Press.

. 1998. "The Emotions of Protests: Affective and Reactive Emotions in and around Social Movements." Sociological Forum 13: 397-424.

—. 2006. "Motivation and Emotions." Pp. 157-71 in Oxford Handbook of Contextual Political Studies, edited by Robert Goodin and Charles Tilly. Oxford: Oxford University Press.

and Dorothy Nelkin. 1992. The Animal Rights Crusade: The Growth of a Moral Protest. New York: Free Press.

and Jane D. Poulsen. 1995. "Recruiting Strangers and Friends: Moral Shocks and Social Networks in Animal Rights and Anti-Nuclear Protests." Social Problems, 42(4): 493-511. 
Jerolmack, Colin. 2003. "Tracing the Profile of Animal Rights Supporters: A Preliminary Investigation." Society \& Animals 11(3): 245-63.

Kane, Anne. 2001. "Finding Emotions in Social Movements Processes: Irish Land Movement Metaphor and Narratives," in Jeff Goodwin, James M. Jasper and Francesca Polletta (eds.) Passionate Politics: Emotions and Social Movements. Chicago: University of Chicago Press.

Kim, Hyojoung. 2002. "Shame, Anger and Love in Collective Action: Emotional Consequences of Suicide Protest in South Korea, 1991." Mobilization 7(2): 159-76.

Kornhauser, William. 1959. The Politics of Mass Society. Glencoe, Ill: The Free Press.

Kruse, Corwin R. 1998. "Who Said That? Status Presentation in Media Accounts of the Animal Experimentation Debate." Society \& Animals 6: 235-43.

Lasswell, Harold. 1930. Psychopathology and Politics. Chicago: University of Chicago Press.

Le Bon, Gustave. [1896]1960. The Crowd: A Study of the Popular Mind. New York: Viking Press.

Lowe Brian M. and Caryn F. Ginsberg. 2002. "Animal Rights as a PostCitizenship Movement." Society \& Animals 10(2): 203-15.

McCarthy, John and Mayer Zald. 1973. The Trend of Social Movements in America: Professionalization and Resource Mobilization. Morristown: General Learning Press.

. 1977. "Resource Mobilization and Social Movements: A Partial Theory." American Journal of Sociology 82: 1212-41.

McPhail, Clark. 1991. The Myth of the Maddening Crowd. New York: A. de Gruyter.

Mika, Marie (2006). "Framing the Issue: Religion, Secular Ethics and the Case of Animal Rights Mobilization." Social Forces 85(2): 915-41.

Miller, Neal and John Dollard. 1941. Social Learning and Imitation. New Haven: Yale Press.

Park, Robert. 1972. The Crowd and the Public, and Other Essays. Chicago: University of Chicago Press.

Plous, Scott. 1991. "An Atttiude Survey of Animal Rights Activists." Psychological Science 2(3): 194-6.

Scheff, Thomas. 1997. Emotions, the Social Bond and Human Reality: Part/Whole Analysis. Cambridge: Cambridge University Press.

Singer, Peter. 1975. Animal Liberation. New York: Avon Books.

Smelser, Neil. 1962. Theory of Collective Behavior. NY: The Free Press. The Buenos Aires Herald. 2003. "PETA pesters KFC in Paris," 17 July. 
The Star Phoenix. 2001. "Minister Warns PETA to Leave Kids Alone," 8 December.

The Virginian-Pilot. 2000. "PETA's Zeal Pushes the Envelope Too Far For Some," 3 December.

Tilly, Charles. 1978. From Mobilization to Revolution. Reading, MA: Addison-Wesley.

Turner, Ralph, and Lewis Killian. 1957. Collective Behavior. Englewood Cliffs, NJ: Prentice-Hall.

Washington Post (1983) "She's a Portrait of Zealotry in Plastic Shoes," 13 November, pg. B10.

White Jr., Lynn. 1967. "The Historical Roots of our Ecological Crisis," Science 155: 1203-1207 